\title{
A Conceptual Use of ICT to Approach Municipal Waste Problem
}

\author{
Pratima Pandit Wagh \\ University of Pune, India
}

\begin{abstract}
One of the greatest challenges facing developing countries is the unhealthy disposal of solid waste which resulted from human activities of development and survival. Awareness and attitude of people in the community appear to be crucial. The problem of waste management has arisen recently in developing countries where there is little history of the implementation of formal and informal community environmental education awareness program. Community participation significantly reduces the cost of waste collection. Information communication technology (ICT) significantly assists the acquisition and amalgamation of knowledge, offering developing countries unprecedented opportunities to enhance educational systems. To gauge the effectiveness of raising awareness regarding domestic solid waste management (SWM) within the society using computer aided tools (CAL), the present research was carried out. The study was conducted to find knowledge of college students with respect to Solid waste management by using developed communication methods. Sample study was conducted with 50 students. Preliminary data was collected by using questionnaire, before and after employing CAL tool and analyzed by using 't test'.

Development of effective knowledge regarding SWM using multimedia package is guiding factor in this project. The findings suggest that CAL tool developed by investigator were effective in raising knowledge of students regarding SWM.
\end{abstract}

\section{Introduction}

Information and communication technology (ICT) in education is use of information and communication as a tool to enhance teaching and learning. Educational ICT tools can be divided into three categories:

1. Input source

2. Output source

3. Others.

In this research paper, input source is the student's response system and output source is the interactive display with others such as audiovisuals. Worldwide research has shown that ICT can lead to improved student learning and better teaching methods. A report made by the national institute of multimedia education in Japan, proved that an increase in student exposure to ICT in education through curriculum integration had a significant and a positive impact on student achievement especially in terms of knowledge, comprehension, practical skill and presentation skill in subject areas such as mathematics, science and social studies.

The main advantage of ICT tools for education on domestic waste management:

1. Through ICT images- they can be easily used in teaching and improving the retentive memory of students.

2. Through ICT, teachers can easily explain complex instructions and ensure students comprehension through audiovisual or by using graphics.

3. Through ICT teachers are able to create interactive classes and make the lessons more enjoyable that could improve student concentration or interest in the subject.

Thus, integrating ICT into education is being considered a catalyst tool for educators/education administrators in the world to enhance education [1].

Solid waste generation is a continually growing problem at global, regional and local levels. Solid wastes are those organic and inorganic waste materials produced by various activities of the society, which have lost their value to the first user. Improper disposal of solid wastes pollutes all the vital components of the living environment (i.e., air, land and water) at local and global levels. Urban society rejects and generates solid material regularly due to rapid increase in production and consumption. The problem is more acute in developing nations than in developed nations, as their economic growth as well as urbanization is more rapid. This necessitates management of solid waste at generation, storage, collection, transfer and transport, processing, and disposal stages in an environmentally sound manner in accordance with the best principles of public health, economics, engineering, conservation, aesthetics and environmental considerations. Thus, solid waste management includes all administrative, financial, legal, planning, and engineering functions.

One of the greatest challenges facing developing countries is the unhealthy disposal of solid waste which resulted from human activities of development and survival. It is a problem recognized by all nations at the 1992 Conference on Environment and Development, and regarded as a major barrier in the path towards sustainability. Environmental Impact of Solid Waste Disposal on Land-When solid waste 
is disposed off on land in open dumps or in improperly designed landfills (e.g. in low lying areas), it causes the following impact on the environment.

(a) Ground water contamination by the leachate generated by the waste dump

(b) Surface water contamination by the run-off from the waste dump

(c) Bad odor, pests, rodents and wind-blown litter in and around the waste dump

(d) Generation of inflammable gas (e.g. methane) within the waste dump

(e) Bird menace above the waste dump which affects flight of aircraft

(f) Fires within the waste dump

(g) Erosion and stability problems relating to slopes of the waste dump

(h) Epidemics through stray animals

(i) Acidity to surrounding soil and

(j) Release of green house gas

The processes of storage, collection, transport, treatment and disposal of wastes all have the potential to pollute the environment and particularly groundwater due to uncontrolled migration of fluids (leachate) derived from the wastes. In addition to the potential for groundwater pollution at sites where wastes are produced and stored prior to collection, sites associated with the treatment and disposal of wastes, where leachate may be generated include: landfills (both controlled as sanitary landfill or uncontrolled as open dumps),Scrap-yards; cemeteries; waste collection and processing facilities; and composting facilities.

Human activities create waste, and the ways that waste is handled, stored, collected, and disposed of can pose risks to the environment and to public health. Rapid population growth overwhelms the capacity of most municipal authorities to provide even the most basic services. According to a United Nations Development Programme survey of 151 mayors of cities from around the world, the second most serious problem that city dwellers face (after unemployment) is insufficient solid waste disposal, typically one- to two-thirds of the solid waste that is generated is not collected. The uncollected waste is dumped indiscriminately in the streets and in drains, contributing to flooding, breeding of insect and rodent vectors, and spreading of diseases. Even waste that is collected is often disposed of in uncontrolled dumpsites or burned, polluting water resources and the air. In many cities, municipal solid waste (MSW) contains human and animal excrement as well as hazardous chemical pollutants and sharps.

All facilitate disease and injury, especially among children, rag pickers, and employees in the waste management sector. Studies have shown that a high percentage of workers who handle refuse and of individuals who live near or on disposal sites are infected with gastrointestinal parasites, worms, and related organisms. Contamination of this kind is likely at all points where waste is handled There is strong evidence which suggests that individual or group awareness and attitudes towards waste generation and management is critical in the effort to respond to the waste management challenge, which ultimately play an important role in providing answer to environmental problem. It has been established that for a nation to attain an improved sustainable environment that is devoid of nuisance, pollution etc., the participation of the citizens must be encouraged and promoted. The problem of waste management has arisen recently in developing countries where there is little history of the implementation of formal and informal community environmental education awareness program. Community participation significantly reduces the cost of waste collection. Public awareness about proper solid waste management is increasing, but the pace is slow. The changing consumption patterns of the city's inhabitants have altered the composition of the waste stream to mostly plastic materials. Clean campaigns and other educational programs can change public attitudes and create environmental awareness and the proper behavior toward minimizing volume. This may involve messages such as keeping garbage bins in good locations; buying goods without unnecessary packaging; returning packaging materials to production sites; returning products for collective disposal; and recycling items such as used furniture, electrical, and electronic appliances.

The initiation of such program is essential to rapidly educate the public and facilitate the development of environmental friendly community. Unhealthy disposal of solid waste is considered as one of the most important problems in many societies. The commencement of community environmental education awareness program is essential to rapidly educate the public and facilitate the development of environmentally friendly community waste behavior. To be successful, useful programs should be designed to engage their target audiences in not only increasing their environmental knowledge but their environmental skills, attitudes and behavior as well. Accordingly, a first step in the program design process is to establish the prior knowledge of specific age groups, covering such categories as the level of knowledge, its sources and everyday application as well as target audiences.

The application of knowledge management approach and strategy is crucial for inculcating a change of attitude towards improving the management of waste [2]. Efficient management of waste is a global concern requiring extensive research and development works towards exploring newer application for a sustainable and environmentally sound management. [3]. Municipal waste management problems are basically due to 
limited formal low level of public education in waste management and due to their attitude towards it.

The menace of unhealthy disposal of domestic solid waste is one of the important environmental concerns that need to be addressed.

Environment education is essential, which promote environmental awareness among all sections of the society; by using different media including films, audio, visual and print, etc. Environment education can be carried out, for spreading messages concerning environment and awareness; and to mobilize people's participation for preservation and conservation of environment and communication has proved to be important media in this regard.

Communication technologies are a major factor in shaping the new global economy and producing rapid changes in society. Within the past decade, the new ICT tools have fundamentally changed the way people communicate and do business. They have produced significant transformations in industry, agriculture, medicine, business, engineering and other fields. They also have the potential to transform the nature of education-where and how learning takes place and the roles of students and teachers in the learning process.

Scientific advances with multimedia changes the way of information, sources of information and the communication. The pace of changes in technology also changes educational approaches and offers new opportunities to the instructional systems. The use of the multimedia opportunities makes the instruction readily available, more affordable, and limitless accessible, easily comprehensible. The role of technology in every step of the instructional systems is the requirement of today's world.

For the current study, communications in the Subject of Environment Science is the area of research. For protection of the environment, by using conventional research programs in biotechnology like bioremediation, countless projects are running in various countries, as conventionally in environmental science, sustenance of the environment is most important area of the research. But by using these methods, disposal and conversion of million tons of domestic waste is very difficult task for majority of municipal authorities in various countries as these are time consuming as well as involving costly processes.

The research is regarding the effectiveness of using multimedia for learning and particularly in distant education method. Environmental knowledge of the young demographic is crucial as their perception and actions would determine in providing solutions to potential environmental problems. There is discernible enthusiasm among the young generation to learn via new technology. To determine the potency of CAL tools in generating greater awareness, this research was conducted. Information generated by this study may be of concern and crucial to the schools and colleges. Government of India has mandated the implementation of an environmental component in the curriculum. It is the responsibility of the local school boards to develop, implement and evaluate such a curriculum more genuinely and by means of taking advantages of recent technological progress like by using multimedia. During field study it was observed that students who learned the topic through multimedia package took less time to master the topics, since it is an interactive multimedia, the reinforcement of the selected topic is done and this helped them to remember the concepts easily.

The researcher can evaluate the problem of waste management in broader sense as the remedial measures after production of waste are very costly as well as time consuming. Increased awareness about domestic waste, in the society will definitely play crucial role in solving the problem.

\section{Literature Review}

Ever since effective research is based upon past knowledge, this step helps to eliminate the duplication of what has been done and provides useful hypothesis and helpful suggestions for significant investigation.

While reviewing the research literature the focus was on the studies investigating the development of multimedia package and computer assisted tools in subject environmental science. Domestic SWM is part of environmental science while health aspects are part of medical sciences. Therefore in literature survey both subjects are considered.

The researcher found that a fine deal of research has been done in educational communication in environmental science.

The topic of present study deals with communicating concepts in the environmental science, mainly the issue of domestic SWM and related health aspects using computer assisted learning tool. Hence researches related to the computer aided instruction and multimedia in teaching environmental science was reviewed.

The general teaching model and instructional system design play important role in the development process, therefore literature related to it was undertaken. Self learning, self instructions based researches also reviewed.

To place the study within the context of relevant literature, the reviews are placed under different headings.

\subsection{Communication theories}

Shannon, Claude Elwood suggested that Sender is transmitter which operates on the message in some way to produce a signal suitable for transmission over the channel, and Channel is merely the medium 
used to transmit the signal from transmitter to receiver.

Wilbur Schram also indicated that one should also examine the impact that a message has (both desired and undesired) on the target of the message. Between parties, communication includes acts that confer knowledge and experiences, give advice and commands, and ask questions.

Harold Lasswell in his work 'The Structure and Function of Communication in Society' defined the communication process as Who (says) What (to) Whom (in) What Channel (with) What Effect [4][5].

David K. Berlo, expanded on Shannon and Weaver's linear model of communication and created the Sender-Message-Channel-Receiver Model of communication (SMCR Model) exposed in his work, 'the Process of communication' where communication appears as a regulated process that allows the subject to negotiate with his living environment. David Kenneth Berlo stated that communication appears as a regulated process that allows the subject to negotiate with his living environment. Communication becomes, then, a value of power and influence [6].

How effective and efficient is the use of multimedia for learning in lecture and on the Internet? Most results are anecdotal and show positive outcomes, with students being enthusiastic about new methods of learning. Multimedia may be a means to more effective learning, by itself there is no assurance of increased learning. Performance generally improves when the way material is presented is changed [7].

\subsection{Attitude knowledge awareness based researches}

Clean Bhutan- a Solid Waste Management Project by RSPN (Royal Society for Protection of Nature RSPN (Non-government Organization) to develop waste management alternatives both on rural and urban areas and come up with measures to mitigate climate change and land degradation in the country. Where Activities were to increase level of awareness among various sectors of the society on waste issues and management by developing education and awareness materials; and conducting advocacy and awareness education through various media; as well as demonstration of waste segregation through involvement of schools also concerned.

J. J. Momoh and D. H. Oladebeye, described participation in and attitude towards solid waste recycling in Ado-Ekiti. According to them "attitude" means the extent to which people are aware of, care about and view household waste recycling in their areas.

\subsection{Environmental Education}

UNESCO-UNEP, Environmental education is a process of developing a world population that is aware of and concerned about the total environment and its associated problems, and which has the knowledge, skills, attitudes, motivations and commitment to work individually and collectively toward solutions of current problems and the prevention of new ones.

John Berry, according to him, the component of quantitative methods helps investigator to begin thinking about the methods in educational research. Its aim is to give an insight into the issues. Investigator can choose quantitative methods as part of the research methodology.

\subsection{Multimedia based instructions}

History of Media Use: In a sense, teaching has always been a "multimedia" enterprise; instructors have typically spoken aloud to, drawn pictures, and attempted demonstrations for the benefit of their students. What has changed has been the evolving technology available for combining and delivering that information.

Valerie Frear and John J. Hirschbuhl, according to them, this study examines the effects of Interactive Multimedia instruction upon the variables of achievement and problem solving skills on nonscience majors in an Environmental Science course at a mid-western university. The findings indicate that the Interactive Multimedia had a significant effect on both of the variables. The findings are discussed in terms of the impact on self-study when students are learning outside of the classroom in a distance learning environment.

\subsection{Teaching models and self-instructional design}

According to Williams A., questionnaires are used in a wide range of settings to gather information about the opinions and behavior of individuals. This paper discusses the issues that should be considered when designing and undertaking a questionnaire study.

\subsection{Construction of instructional design}

According to D. J. Marshall EME, investigator also studied cognitive theories, which gave emphasis on Programmed Instruction $\rightarrow$ Ed Technology, Direct instruction, Personalized System of Instruction, Computer assisted instruction, Evolution/Emphasis of behaviorism as well as Domains of learning teachers roles, Students roles. 
Hagengruber, D. \& Hungerford, H., The GTM schematic diagram suggested by these researchers illustrates components of the instructional process recommended for preparing for instruction.

\subsection{Computer aided instruction}

Min, Lin and W. Michael Reed studied the practical application of computers in learning. The comparative study of pre test and post test was considered on different factors.

\subsection{Solid waste management (SWM)}

Chris Zurbrugg, Rehan Ahmed, Roland Schertenleib states that the waste generated by the fast growing cities in developing countries is increasingly beyond the collection capacity and financial limitations of the municipal administrations.

Shimizu, K. emphasizes people's participation in waste management. According to researcher wider awareness/education, responsibility and knowledge sharing, creation of innovative market-base instruments, private initiatives to enhance income and employment opportunities, and possibility of leasing MSW management services and cost sharing through service fees.

For data analysis the best way to begin to appreciate the kind of statistics that investigator might employ in his own research is to have a look at what others have done; consequently the paper by John Berry and Pasi Sahlberg which is 'Investigating pupils' ideas of learning' was used to identify the statistics that can be used. The section 'Findings'contains some of the important measures that researcher use in quantitative research methods. Likewise SAS statistics tutorials studied which explain the use and interpretation of standard statistical analysis techniques for Scientific Research. The examples include how-to instructions for SAS Software. For Statistical hypothesis testing and for statistical analysis software like SIS and MY STAT is used.

The environmentally sound management of solid wastes issue had received the attention of international and national policy making bodies and citizens. The success of SWM strongly depends on people's behavior [8][9]. Responsible behavior or changes in waste disposal practices can best be made when people understand the issue.

ICT is an indispensible part of the contemporary world. The pervasiveness of ICT has brought about rapid technological, social, political and economic transformation, which has eventuated in a network society organised around ICT [10]. In research ICT provides quicker and easier access to more extensive and current information [11]
According to Culp Honey and Mandinach, ICT is a change agent. It is equally good for geographically dispersed audiences and it also helps students to collect and make sense of complex data. As change agent it catalyses various other changes in the content, methods and overall quality of teaching and learning. [12]

In order to conduct this research among the undergraduate students, the investigator has proposed following objectives.

a. To diagnose knowledge of the students about domestic solid waste management.

b. To raise level of knowledge in the target group regarding domestic solid Waste management by using computer assisted learning tool developed by investigator.

c. To analyze effectiveness of method on the target group.

\section{Tools used}

Data collection instrument i.e. tool is developed, which is questionnaire, after formulation of the concept and hypothesis.

Based on reviewed literature, a questionnaire was designed on student's knowledge about domestic solid waste management. Total 30 questions were included in the questionnaire in order to determine the extent to which students associated with these issues.

Each question in the questionnaire, having four answers, designated as a, b, c and d. The sample scale instrument includes 4-point Likert scale type questions responses that are scored from 1 to 4 and correspond to " $1=$ disagree", " $2=$ neither agree nor disagree", " 3 = agree", " 4 = strongly agree". The instrument was validated with the assistance of three experts in research and environmental sciences as well as from the faculty of education.

\section{Variables - Related to problem}

In this research paper, the knowledge of survey respondents, regarding solid waste management of domestic waste is variable, As variables are the conditions or characteristics that the experimenter manipulates, controls or observes which can be changed when experimenter introduces the appropriate knowledge upgrading methods such as by employing computer assisted learning tool developed by investigator.

It is necessary to distinguish among key variables, explicative and structure variables: key variables are those which describe the topic under investigation, in present research the study is relative to awareness regarding SWM and diseases caused by the improper waste handling, key variables will be relative to SWM. 
Explicative variables are all those variables which might be correlated (linked) to the key variables, for example in the case of SWM it could be the environment, attitude, knowledge, and so on. Structure variables are age, sex, education, profession; variables which are usually used to describe the sample of the study. In order to avoid choosing explicative variables which might be irrelevant it is important to be helped by experts who have a good knowledge of the subject. Accordingly the assistance from the experts in the field of education and environmental science was taken. In this study two variables are used, namely - pre test score is variable 1 and post test score is variable 2 .

\section{Methodology}

\subsection{Selection of the sample}

Measuring every single piece of item in population is just not practical. That is why researchers developed and used statistical methods to solve problems. The most practical way to do it is, to draw a sample from the population. For selection of sample, rough estimates of the size of sample made from knowledge of the degree of precision desired. In statistics, a sample is a subject chosen from a population for investigation; a random sample is one chosen by a method involving an unpredictable component. Random sampling can also refer to taking a number of independent observations from the same probability distribution, without involving any real population. The sample usually is not a representative of the population from which it was drawn. This random variation in the results is termed as sampling error. In the case of random samples, mathematical theory is available to assess the sampling error. Thus, estimates obtained from random samples can be accompanied by measures of the uncertainty associated with the estimate. This can take the form of a standard error, or if the sample is large enough for the central limit theorem to take effect, confidence intervals may be calculated.

For data collection simple random sampling method is used. A simple random sample is selected so that all samples of the same size have an equal chance of being selected from the population. Fifty students, doing their graduation in Science, Commerce \& Arts, were selected as a target group. Random sampling method used for sample collection. These subjects were from various undergraduate colleges in rural as well as from urban areas of the Nasik district of Maharashtra, India.

\subsection{Procedure}

The questionnaire was handed out for data gathering, as in classroom setting for the students to answer and return (pretest).
After the pretest, to increase knowledge about solid waste management with the help of CAL tool i.e. Digital Video Disc (DVD: Prepared by investigator).

The computer aided learning tool used in this study is based on knowledge about domestic solid waste and management of the waste. The health factor also considered here as Solid waste management's direct relation is not only with aesthetics but also with the diseases produced due to unhealthy/unclean environment. This tool is also supplemented with the technological advance in the field of environmental science, information technology and systematic analysis and interpretation. The module was based on the extended case study, format as well as on the basis of ADDIE model considered by Morrison, Ross and Kemp for the investigation of issues. The case study approach was selected for the design of the module as it provides the instructor with a substantial amount of flexibility and control. The instructor can choose the issue, determine methods to be used and make decisions concerning the depth to which the issue will be analyzed. It is an instructional method utilizing both primary and secondary sources to deliver issue-focused information and skills to students and can be used for learners in colleges.

With the help of Digital Video Disc and power point presentation supplemented with pictures, charts, animation etc. on impacts of Solid waste management, with an illustrative lecture was delivered. Each and every doubt put forth by the students was resolved on the spot.

After a week a post test was conducted for the same students and by using same questionnaire. Outcomes were recorded as in Tables 1 and 2. The students responses (pre, post etc) were analyzed by using statistical method based on the significance of the difference between the means of two matched or correlated groups (non independent samples).

5.2.1. The t-Test. Investigator uses this statistical test to compare sample populations and determine if there is a significant difference between their means. The result of the t-test is a ' $t$ ' value; this value is then used to determine the p-value.[13][14].

$\mathrm{t}$ test has many methods that will suit any need. When $\mathrm{t}$ test is used in large samples, the t-test becomes very similar to the $\mathrm{z}$ test. It is very likely that the $\mathrm{t}$ test is most commonly used Statistical data analysis procedure for hypothesis testing since it is straightforward and easy to use. Additionally, it is flexible and adaptable to a broad range of circumstances. There are two types of t-tests, the unpaired and paired t-test. Where unpaired, t-test is used when investigator have independent samples. In other words samples are not directly related to one another. While in Paired t-test samples are related. Investigator collected data before and after some manipulation of subjects. 
5.2.2. P-value. The $p$-value is the probability that ' $t$ ' falls into a certain range. In other words this is the value use to determine if the difference between the means in sample populations is significant. For present research purposes, a p-value $<0.05$ suggests a significant difference between the means of sample population and investigator would reject null hypothesis. A p-value $>0.05$ suggests no significant difference between the means of sample populations and investigator would not reject null hypothesis [15]. A researcher gathers some sample data and observes that the two groups have different average scores. But does this represent a real difference between the two populations, or just a chance difference in samples is a question, therefore use of t-test.

\subsubsection{Hypothesis Testing and the Statistical t-test.} The t-test is probably the most commonly used statistical data analysis procedure for hypothesis testing. In fact, there are several kinds of t-tests, but the most common is the "two-sample t-test" also known as the "Student's t-test" or the "independent samples t-test". The two sample t-test simply tests whether or not two independent populations have different mean values on some measure. The t-test Statistics allows answering of this question. By using the t-test statistic to determine a p-value that indicates how likely researcher could have got these results by chance. By convention, if there is less than $5 \%$ chance of getting the observed differences by chance, reject the null hypothesis and establish a statistically significant difference between the two groups.

5.2.4. Degrees of freedom. Degrees of freedom for unequal and equal variance $\mathrm{t}$-tests $=(\mathrm{n} 1+\mathrm{n} 2)-2$

For paired sample t-test $=$ number of pairs -1

The calculated value exceeds the critical values the HO must be rejected at the level of confidence selected before the test was executed. Both the one and two-tailed results confirm that the $\mathrm{H} 0$ must be rejected and the Ha accepted.

Statistics are a tool, not an aim. Simple inspection of data, without statistical treatment, by an experienced and dedicated analyst may be just as useful as statistical figures on the desk of the disinterested. The value of statistics lies with organizing and simplifying data, to permit some objective estimate showing that an analysis is under control or that a change has occurred. Equally important is that the results of these statistical procedures are recorded and can be retrieved. [16]

The t-test for paired samples was used. This implies that each individual observation of one sample has a unique corresponding member in the other sample. This test is used when the samples are dependent; that is, when there is only one sample that has been tested twice (repeated measures) or when there are two samples that have been matched or "paired"[17][18].

\section{Results}

Results of pre and post test score of the students are recorded in the tabular form which are as follows.

Table 1. Pre and post test score-observation sets

\begin{tabular}{|c|c|c|c|c|c|}
\hline Stne & $\begin{array}{l}\text { Pre test } \\
\text { goove (variable 1) }\end{array}$ & $\begin{array}{l}\text { Post test } \\
\text { fourefvariable 2x }\end{array}$ & St $n$ & $\begin{array}{l}\text { Pre test } \\
\text { poorecivariable } 18\end{array}$ & Poos test \\
\hline i & 32 & t] & 14 & 48 & 49 \\
\hline 2 & 40 & 45 & 15 & 25 & 32 \\
\hline 3 & 37 & 50 & 16 & 27 & 54 \\
\hline 4 & 51 & $\mathrm{k} 2$ & 17 & 15 & 52 \\
\hline 5 & 44 & 44 & 18 & 46 & 79 \\
\hline 6 & 18 & 56 & 19 & 37 & 50 \\
\hline 7 & 29 & 147 & 60 & 38 & 41 \\
\hline 8 & 30 & 118 & 9 & 27 & 46 \\
\hline 9 & 26 & 45 & 92 & 37 & 56 \\
\hline 10 & 38 & 87 & 23 & 40 & 53 \\
\hline 11 & 27 & 02 & 24 & 52 & 72 \\
\hline 12 & 39 & 46 & 35 & 33 & 44 \\
\hline 13 & 36 & 84 & 28 & 23 & 34 \\
\hline
\end{tabular}

Table 2. Pre and post test score-observation sets

\begin{tabular}{|c|c|c|c|c|c|}
\hline Srno & $\begin{array}{l}\text { Pre test spore } \\
\text { (variable 1) }\end{array}$ & $\begin{array}{l}\text { Post test } \\
\text { scorervariable 2) }\end{array}$ & & $\begin{array}{l}\text { Pre test score } \\
\text { o(variabie 1) }\end{array}$ & $\begin{array}{l}\text { Post test } \\
\text { scone(variable 2) }\end{array}$ \\
\hline 27 & 35 & 46 & 39 & 72 & 74 \\
\hline 28 & 39 & 43 & 40 & 50 & 51 \\
\hline 29 & 47 & 49 & 41 & 35 & 41 \\
\hline 30 & 46 & 47 & 42 & 42 & 43 \\
\hline 31 & 29 & 10 & 13 & 29 & 33 \\
\hline 32 & 67 & 63 & 14 & 23 & 32 \\
\hline 33 & 52 & 54 & 45 & 25 & 37 \\
\hline 34 & 29 & 49 & 46 & 27 & 36 \\
\hline 35 & 51 & 54 & 47 & 42 & 49 \\
\hline 36 & 41 & 50 & 48 & 19 & 39 \\
\hline 37 & 41 & 48 & 49 & 16 & 28 \\
\hline 38 & 35 & 40 & 50 & 34 & 39 \\
\hline
\end{tabular}

\subsection{Data analysis}

The student responses (pre, post etc) were analyzed by using t test. Based on Significance of the difference between the means of two matched or correlated groups (non-independent samples).

$\mathrm{t}$ test: As these groups are not independent samples, it is necessary to calculate the coefficient of correlation between the pretest and posttest scores of the participants in the experiment. As the coefficient of correlation is used, the appropriate t test would be based upon given formula as follows:

The number of degrees of freedom (df) would be the number of pairs minus one. Then testing null hypothesis that,

"Computer assisted learning tool will not raise the knowledge about domestic solid waste management" By selecting 5 percent level of significance, using a two-tailed test. 
Hypothesis testing: Is by using Pearson's sample correlation coefficient $(r)$ and by using $t$ test Outcome of paired t-test recorded in Table 3 .

Table 3. t-Test: Paired Two Sample for Means

\begin{tabular}{|l|l|l|}
\multicolumn{1}{l}{} & Variable I & \multicolumn{1}{l}{ Variable 2 } \\
\hline Mean & 37.22 & 47.18 \\
\hline Variance & 112.542449 & 7 \\
\hline Observations & 50 & 50 \\
\hline $\begin{array}{l}\text { Pearson } \\
\text { Correlation }\end{array}$ & 0.758000128 & \\
\hline $\begin{array}{l}\text { Hypothesized } \\
\text { Mean Difference }\end{array}$ & 0 & \\
\hline Df & 49 & \\
\hline t Stat & 9.683482771 & \\
\hline $\begin{array}{l}\text { P(T }-t) \\
\text { one-tail }\end{array}$ & $2.89566 \mathrm{E}-13$ & \\
\hline $\begin{array}{l}\mathrm{t} \text { Critical } \\
\text { one-tail }\end{array}$ & 1.676550893 & \\
\hline $\begin{array}{l}\text { P(T<-t) } \\
\text { two-tail }\end{array}$ & $5.79132 \mathrm{E}-13$ & \\
\hline $\begin{array}{l}\text { t. Critical } \\
\text { two-tail }\end{array}$ & 2.009575199 & \\
\hline
\end{tabular}

Paired Samples t-test on VAR_1 vs. VAR_2 with 50 Cases (n)

Mean VAR_1: 37.22

Mean VAR_2: 47.18 df: 49

$\mathrm{t}=9.683482771$

Two tailed test, using data of post and pre test $\mathrm{P}$-value $=5.79132 \mathrm{E}-13$, i.e. $\mathrm{p}$-value: 0.000

Alternative hypothesis is- true difference in means is not equal to 0 .

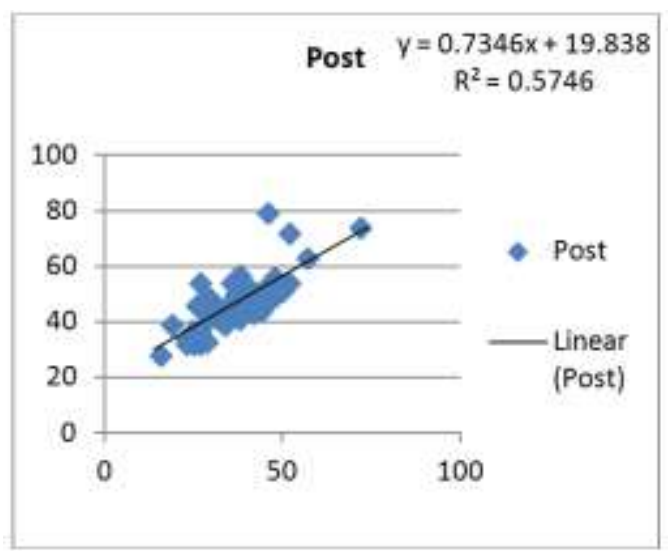

Figure 1. Regression Equation of POST test on PRE test

\section{Discussion}

After analysis on the subject of test scores of students by using frequency distribution proved high positive skewness for pretest scores and negative skewness for posttest scores signifying that comparatively on an average the post test scores of the students who gain knowledge by CAL tool, are prominent as compared to pretest scores. I.e. for educating and accommodating acquaintance among the students, definitely suggesting that present method developed by the researcher is effective in increasing awareness about solid waste management and related health aspect.

At the end of research investigation, during comparison of two data sets of all the participants namely scores before and after applying the method i.e. educating them by means ICT, when analyzed by $t$ test showed that average score of students is increased due to use of computer aided learning method, signifying development of effective computer assisted learning tool as far as the awareness of survey population is concerned.

\section{Conclusion}

After analysis on the subject of test scores of students by using frequency distribution proved high positive skewness for pretest scores and negative skewness for posttest scores signifying that comparatively on an average the post test scores of the students who gain knowledge by power point presentation are eminent as compared to pretest scores. I.e. for educating and accommodating acquaintance among the students, definitely suggesting that present method developed by the researcher is effective in increasing awareness about solid waste management and related health aspect.

Subsequent to the frequency distribution when two data sets from two groups i.e. from male and female student's compared by using $\mathrm{z}$ test, it is observed that there is no significant difference between average increase in scores of male and female students. As two means do not differ significantly therefore the conclusion is 'present method is equally effective for both groups as far as their knowledge and attitude is concern'.

At the end of research investigation, during comparison of two data sets of all the participants namely scores before and after applying the method i.e. educating them by means of power point presentation with illustrative lecture when analyzed by $\mathrm{t}$ test showed that average score of students is increased due to use of computer aided learning method, signifying development of effective computer assisted learning tool as far as the awareness of survey population is concerned.

As the t Critical two -tail value of 2.009575199 exceeds $t$ critical value of 9.683482771 for two tailed test at the .05 level for 49 degrees of freedom, we rejected null hypothesis, concluding that initial score of pretest is less than that of final score of posttest of survey respondents, when lecture with power point presentation is delivered. Indicating that, there is increased awareness regarding domestic waste 
management and related health aspects i.e. significant difference in attitude of students. Secondly researcher concludes that there is considerable difference in student's knowledge about domestic waste management and related heath aspect after learning with the help of strategies developed by investigator.

\section{References}

[1] Ref www.elmoglobal.com/en/html/ict/ol.aspx (Access date: 29 January, 2017)

[2] Beatrice Abila and Jussi Kantola (2013), "Municipal solid waste management problems in Nigeria: Evolving knowledge management solutions", international journal of environmental ecological, geological, geophysical engineering (7), 6 .

[3] Q.H Bari, K.M Hasan, M.E Haque (2012) "Solid waste recycling in Rajshahi city of Bangladesh" Waste management (32)11, PP 2029-2036.

[4] Pankuch, B. (1998), "Abstract: How effective and efficient is the use of multimedia for", Multimedia in Lectures and on the World Wide Web, Princeton University, spring, p.17.

[5] Lasswell, H.D. (1948) "The Structure and Function of Communication in Society", the Communication of Ideas. Editor, Lyman Bryson, New York: Institute for Religious and Social Studies, Jewish Theological Seminary of America, p. 37.

[6] Cointreau, S. (2001), "Declaration of principles for sustainable and integrated solid waste management", World Bank, Washington, D.C., pp.4.

[7] Wilbur, S.(1961), "How Communication Works, the Process and Effects of Mass Communication", editor, Wilbur Schramm, Urbana, Ill.: The University of Illinois Press, pp. 5-6.

[8] NEERI (National Environmental Engineering Research Institute) 1995, "Strategy Paper on SWM in India", Nagpur, India.

[9] Diaz, L.F., Savage, G., Goluke, C. (2002), "Solid waste composting", In Handbook of Solid Waste Management, G. Tchobanoglous and F. Kreith (eds.). McGraw-Hill, Chapter 12, pp 50-53.

[10] Castells "The rise of the network society" [vol 2] oxford: Blackwell publishers, 1996.

[11] Yusuf M.O. and Onasanya S.A. [2004] Information and communication technology [ICT] and technology in tertiary institution in E.A. Ogunsakin [ED] teaching in tertiary institutions [pp-67-76].

[12] Culp, K. M, Honey, M. and Mandinach, E. (2003) A retrospective in 20 years of educational technology policy. http://www.nationaliedtechplan.org/participate/20years.pdf (Access date: 30 October, 2016).
[13] Richard Mankiewicz (2004). The Story of Mathematics (Paperback ed.). Princeton, NJ: Princeton University Press. pp. 158.

[14] John J.; Robertson, Edmund F., "William Sealy Gosset", Mac Tutor History of Mathematics archive, University of St Andrews.

[15] Wasserstein, Ronald L.; Lazar, Nicole A. (7 March 2016). "The ASA's Statement on p-Values: Context, Process, and Purpose". The American Statistician. 70 (2):129-133. doi:10.1080/00031305.2016.1154108.

(Access Date: 30 October, 2016).

[16] Resnik, D. (2000) Statistics, ethics, and research: an agenda for educations and reform, Accountability in Research. 8: 163-88.

[17] UNESCO (1977), "Education and the challenges of environmental problems", Report of Intergovernmental Conference on Environmental Education, Paris.

[18] Best, J. and Kahn, J. V., (1999) Research in Education, (17th ed.), Prentice Hall of India pvt ltd: New Delhi, pp. 198, 207-352. 